
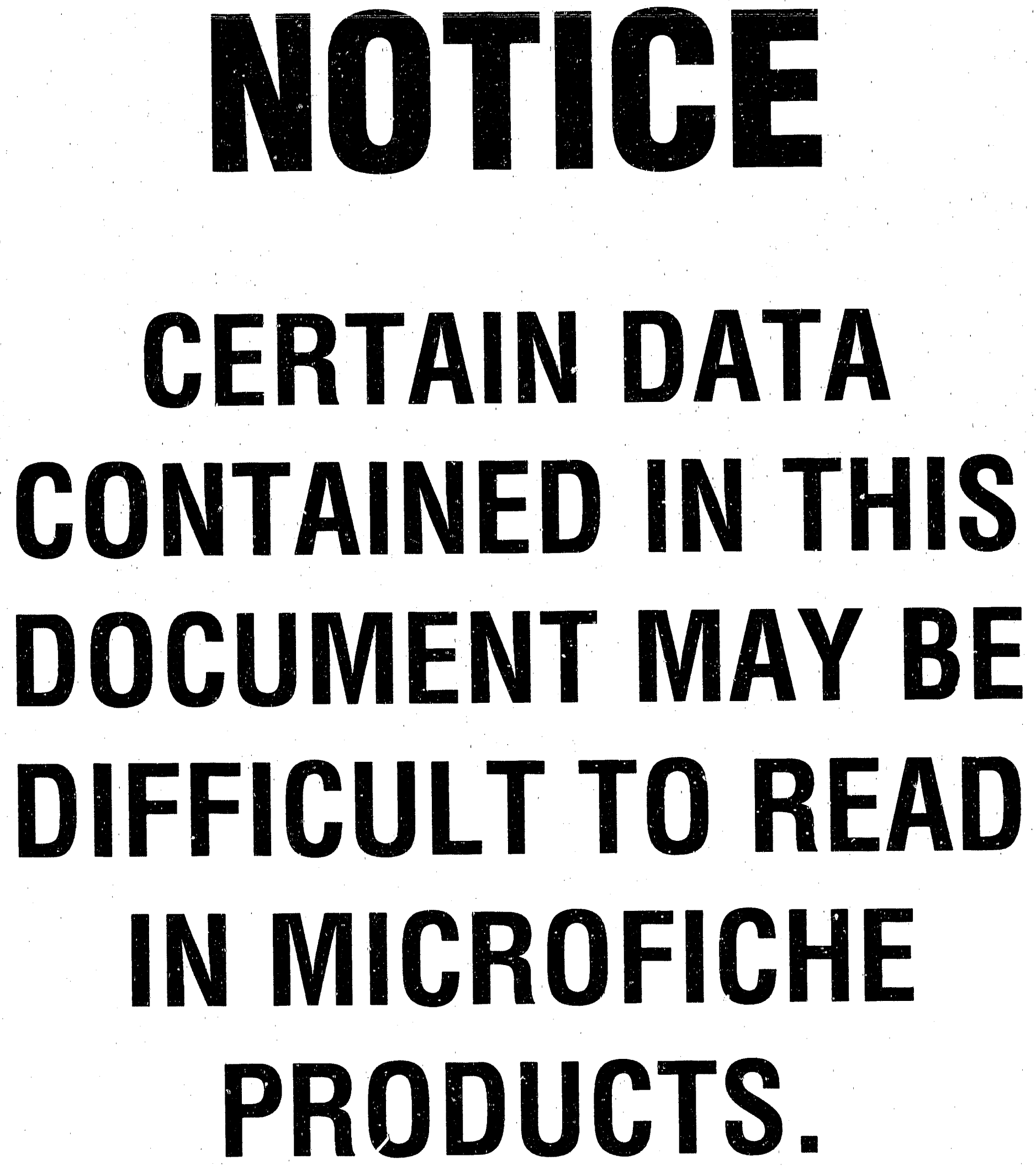


\title{
LASER-INDUCED FLUORESCENCE OF PHOSPHORS FOR REMOTE CRYOGENIC THERMOMETRY
}

\author{
D. L. Beshears \\ G. J. Capps \\ M. R. Cates \\ C. M: Simmons
}

Applied Technology Division

S. W. Schwenterly

Fusion Energ; Division

Oak Ridge National Laboratory

Oak Ridge, Tennessec

\section{DISCLAIMER}

This report was prepared as an account of work sponsored by an agency of the United States Government Neither the United States Government nor any agency thereof, nor any of their emplovees, makes any warranty, express or implied, or assumes any legal liability or responsi. bility for the accuracy, completeness, or usefulness, of any information, apparatus, product, or process disclused, or represents that its use would not infringe privately uwned rights. Refer ence heren to any specific commercial product, proxess, or service by trade name, trademark. manuficturer. or otherwise does not necessarily constitute or imply its endorsement, iecommendatun, favorng by the United States Government or any agenoy therew The vew and anmons of authors expressed herein do rot necessurily state or refles those of the Unted Siates Government ur any agency thereot.

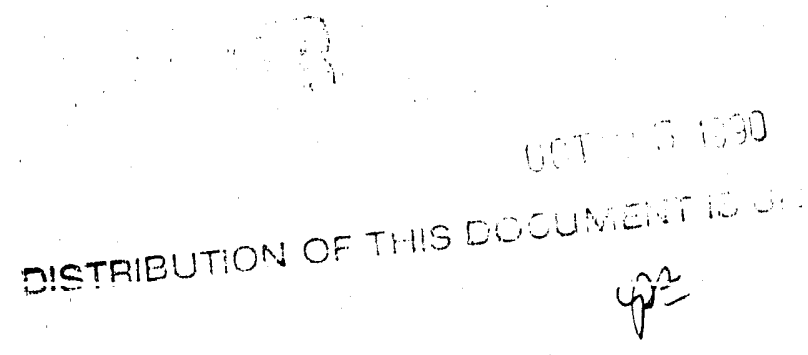




\title{
Laser-induced fluorescence of phosphors for remote cryogenic thermometry
}

\author{
D. L. Beshears \\ G. J. Capps \\ M. R. Cates \\ C. M. Simmons \\ S. W. Scliwenterly
}

Oak Ridge National Laboratory*

Oak Ridge, Tennessee 37831-7280

\begin{abstract}
Remote cryogenic temperature measurements can be made by inducing fluorescence in phosphors with temperature-dependent emissions and measuring the emission lifetimes. The thermographic phosphor technique can be used for making precision, non-contact, cryogenic temperature measurements in electrically hostile environments, such as high DC electric or magnetic fields. NASA is interested in utilizing these thermographic phosphors for mapping hot spots on cryogenic tank walls. Europium-doped lanthanum oxysulfide $\left(\mathrm{La}_{2} \mathrm{O}_{2} \mathrm{~S}: \mathrm{Eu}\right)$ and magnesium fluorogermanate doped with manganese $\left(\mathrm{Mg}_{4}(\mathrm{~F}) \mathrm{GeO}_{6}: \mathrm{Mn}\right)$ are suitable for low-temperature surface thermometry. Several emission lines, excited by a $337 \mathrm{~nm}$ UV laser, provide fluorescence lifetimes having logarithmic dependence with temperatures from 4 to 125 Kelvin. A calibration curve for both $\mathrm{La}_{2} \mathrm{O}_{2} \mathrm{~S}:$ Eu and $\mathrm{Mg}_{4}(\mathrm{~F}) \mathrm{GeO}_{6}: \mathrm{Mn}$ are presented as well as emission spectra taken at room temperature and 7 Kelvin.
\end{abstract}

\section{INTRODUCTION}

Surface temperatures of moving objects, objects restricted from direct contact with a thermal probe, or large areas were temperature surveys are needed can be very diflicult to measure with conventional techniques. One method of accomplishing these measurements is to coat the surface area of interest with a temperature dependent phosphor and induce lluorescence by excitation with ultraviolet radiation. The emission lifetime and intensity at certain wavelengths are directly dependent on temperature. Studies with various doped phosphors at high temperatures have been effected with great success and have added a new dimension to thermometry. A need for this remole thermal ability at cryogenic temperatures exists in areas such as space vehicles and exploratory machinery. This paper will investigate the use of lanthanum oxysulfide doped with europium $\left(\mathrm{La}_{2} \mathrm{O}_{2} \mathrm{~S}: \mathrm{Eu}\right)$ and magnesium fluorogermanate doped with manganese $\left(\mathrm{Mg}_{4}(\mathrm{~F}) \mathrm{GeO}_{6}: \mathrm{Mn}\right)$ for temperaturc measurements over the range of 4 to $80 \mathrm{~K}$. Temperature calibration curves for $\mathrm{La}_{2} \mathrm{O}_{2} \mathrm{~S}: \mathrm{Eu}$ and $\mathrm{Mg}_{4}(\mathrm{~F}) \mathrm{GeO}_{h}: \mathrm{Mn}$ at cryogenic temperatures will be presented.

\section{THERMOGRAPHY PHOSPHORS CHOSEN FOR CRYOGENIC MEASUREMENTS}

Strong temperature dependence exist in the lanthanum oxysullide phosphor because of the competition between nonradiative-lattice de-excitation processes and photon-emitting de-excitation within the curopium electronic levels. The trivalent europium ion has several metastable states from which lluorescent emission occurs. Details of this interaction are described by Fonger and Struck.'

* Oak Ridge National Laboratury is operated by Martin Marietla Energy Systems, Inc., for the U.S. Department of Energy under contract DE-AC05-84OR2140K) 
From the studies by Fonger and Struck, as well as earlier Oak Ridge studies ${ }^{1-4}$ of $\mathrm{La}_{2} \mathrm{O}_{2} \mathrm{~S}: \mathrm{Eu}$, its temperature dependency from approximately 80 to above $500 \mathrm{~K}$ is well documented. The room temperature emission and excitation spectra for $\mathrm{La}_{2} \mathrm{O}_{2} \mathrm{~S}: \mathrm{Eu}$ are shown in Fig. 1.

The second phosphor chosen for our evaluation was $\mathrm{Mg}_{4}(\mathrm{~F}) \mathrm{GeO}_{6}: \mathrm{Mn}$. The emission lifetime or fluorescent decay time exhibits a reproducible variation over a range of temperature between $-180^{\circ} \mathrm{C}$ and $+450^{\circ} \mathrm{C} .^{5}$ We will explore the region between absolute zero and $-180^{\circ} \mathrm{C}$. Figure 2 shows the room lemperature emission and excitation spectra for $\mathrm{Mg}_{4}(\mathrm{~F}) \mathrm{GeO}_{6}: \mathrm{Mn}$.

Figures 3 and 4 show emission spectra for each of the phosphors for a given cryogenic temperature. In our initial screening process we found that both the $\mathrm{La}_{2} \mathrm{O}_{2} \mathrm{~S}: \mathrm{Eu}$ and $\mathrm{Mg}_{4}$ (F) $\mathrm{GeO}_{6}$ :Mn showed excellent potential in the temperature range of interest. With the $\mathrm{La}_{2} \mathrm{O}_{2} \mathrm{~S}:$ Eu the fluorescence lines of interest for the cryogenic temperatures were 418 and $446 \mathrm{~nm}$, although we also monitored the 514-, 538-, and 624-nm lines. When looking at the $\mathrm{Mg}_{4}(\mathrm{~F}) \mathrm{GeO}_{6}: \mathrm{Mn}$, the 657-nm lines showed cryogenic temperature dependence. We also monitored the 623- and 638$\mathrm{nm}$ lines.

Measurements with $\mathrm{La}_{2} \mathrm{O}_{2} \mathrm{~S}:$ Eu near room temperature have exhibited temperature dependency as to allow determinations with $<0.5^{\circ} \mathrm{C}$ uncertainty. In these initial feasibility studies, accuracy was not the issue but rather determining if phosphor thermography could be used to measure cryogenic temperatures in the region of 4 to $80 \mathrm{~K}$. Thus, the main objective of this report is to present data which have been collected on $\mathrm{La}_{2} \mathrm{O}_{2} \mathrm{~S}: \mathrm{Eu}$ and $\mathrm{Mg}_{4}(\mathrm{~F}) \mathrm{GeO}_{6}: \mathrm{Mn}$ at temperatures ranging from 4 to $80 \mathrm{~K}$

\section{DESCRIPTION OF THE THERMOGRAPHIC CRYOSTAT}

The design objective was to provide a variable-temperature cryostat that could be used to irvestigate various phosphors' responses to cryogenic temperatures from liquid nitrogen (LN) down to liquid helium (LHe) temperatures. Such an apparatus was designed and fabricated and will be described in the following paragraphs.

The cryostat shown in Figs. 5 and 6 was designed to fit an existing rescarch Dewar. Figure 7 gives a detailed cross-sectional view of the thermographic phosphor sample holder. The phosphor was placed in a $0.64-\mathrm{cm}$ diam cup in the end of a copper spindle. A heater was wrapped around the spindle just below the phosphor cup. A thermocouple (Au-0.07\% Fe vs chromel) junction was mounted just below the cup to provide for temperature measurements. The reference junction for this thermocouple was immersed in the LHe bath at $4.16 \mathrm{~K}$. Thus, the temperature differentials relative to the LHe bath temperature could be measured. Using standard thermocouple tables, an accuracy of $>1 \mathrm{k}$ could be obtained. A vishay cryogenic linear temperature sensor (CLTS) was also mounted on the copper spindle to allow additional absolute temperature measurements with a precision of $-2 \mathrm{k}$.

The copper spindle was sealed into a $0.64-\mathrm{cm}$ Swagelok fitting that was welded into a long, 1.91 . $\mathrm{cm}$-diam, stainless-steel tube. Thus, the measurements could be carried out with either vacuum or helium vapor around the phosphor. Two optical libers were mounted in the tube to bring in the 337 $\mathrm{nm}$ ultraviolet (UV) light from a nitrogen laser and Iransmit the emitted light back out to the monochrometer. The Swagelok fitting could be unscrewed (1) allow a new phosphor to be evaluated. A piece of 1.27 -cm-diam thin-wall stainless-steel tubing extended from the spindle down into the LHe bath. A 25-turn-kength of $0.1-\mathrm{cm}$-diam copper wire was wrapped around this tube to provide a heat leak from the bath to the spindle. The thermecouple, CI.TS, and heater leads come through this 
tube and exited into the bath. The leads were hermetically sealed into the end of the copper spindle with Stycast 2850 FT epoxy.

In operation, the phosphor tube and Dewar were evacuated and purged with helium gas. The Dewar was then filled with LHe to the desired level. If the temperatur e desired was at or near LHe temperature, the level was raised until the copper spindle was inmersed. The temperature of the phosphor could be increased by elevating the spindle with respect to the LHe level or energizing the heater to provide fine temperature control. The temperature could be controlled within $0.1 \mathrm{~K}$ during a measurement sequence on the phosphor.

\section{SETUP FOR CRYOGENIC TEMPERATURE MEASUREMENTS}

A schematic of the screening and calibration setup is shown in Fig. 8. A pulsed-nitrogen laser (337-nm wavelength) was used to produce the excitation signal. The signal was carried from the laser via an optical fiber $(600-\mu \mathrm{m}$-diam, plastic-coated silica) to the sample that consisted of a thin packed film of the phosphor of interest. The phosphor was housed in the copper spindle cup described under in the previous section where the technique for controlling the temperature is also described. The cooling liquid was supplied by a $1000-\mathrm{L}$ LHe storage Dewar to the cryogenic research Dewar.

The fluorescent emission signal was picked up by the same type of optical fiber mentioned previously and carried into a monochrometer where the wavelength was selected. The signal then entered the photomultiplier tube from which the amplified signal was displayed on a Tektronics 7854 waveform-analyzing oscilloscope. The fluorescent signals were then permanently stored on a computer via a GPIB interface. F uorescent-emission spectral information was also obtained at different temperature levels by auto atically varying the emission wavelength on the monochrometer and recording the output of the pt otomultiplier on a strip-chart recorder.

\section{COLLE.CTING AND ANALYZING THE TEMPERATURE DATA}

Several runs were made in each temperature range for the $\mathrm{La}_{2} \mathrm{O}_{2} \mathrm{~S}$ :Eu, and each temperature datum was the average of four individual readings. This calibration study concentrated on a temperature range between 4 and $80 \mathrm{~K}$, and severai higher-temperature points were taken to verify concurrence with previously obtained data. The 446-nm-emission line representing the ${ }^{5} \mathrm{D}_{3}$ transition was examined, and a plot of the results of this investigation, as well as our carlicr investigation. are shown in Fig. 9. The temperature, in Kelvin, is plotted against the log of the emission lifetime in microseconds.

Program limitations did not allow a thorough investigation of the $\mathrm{Mg}_{4}(\mathrm{~F}) \mathrm{GeO}_{6}$ :Mn phosphor. A cursory at the $\mathrm{Mg}_{4}(\mathrm{~F}) \mathrm{GeO}_{6}: \mathrm{Mn}$ indicated that it could be use as a cryogenic thermometer. The 657 non emission line was examined over the range of 13 to $145 \mathrm{~K}$. The data are plotled in Fig. 12 as the temperature in Kelvin vs the log of the emission lifetime in milliseconds. In the future, we hope to be able to perform a more extensive and detailed calibration study of the $\mathrm{Mg}_{4}(1) \mathrm{GeO}_{6}: \mathrm{Mn}$.

\section{CONCLUSION}

Both the curopium-doped lanthamum oxysulfide, and mangancese doped magnesium lluorogermanate phosphors can be used for remote cryogenic temperature sensing. Moving, inaccessible, or hazardous cold environments can be thermally investigated using these phosphor techniques. Additional research is needed to fully exploit the potential in this area. Diflerent 
phosphors and rare earths should be investigated.

\section{ACKNOWLEDGEMENTS}

This work was performed in support of the National Aeronautics and Space Administration Marshall Space Flight Center, Cryogenic Fluids Technology Office, at the Oak Ridge National Laboratory, operated by Martin Marietta Energy Systems, Inc., for the U. S. Department of Energy: under contract DE-AC05-84OR21400.

\section{REFERENCES}

1. W. H. Fonger and C. W. Struck, "Eu ${ }^{+++5} \mathrm{D}$ Resonance Quenching to the Charge-Transfer States in $\mathrm{Y}_{2} \mathrm{O}_{2} \mathrm{~S}, \mathrm{La}_{2} \mathrm{O}_{2} \mathrm{~S}$, and LaOCl," J. Chem. Phys. 52 (12), 6364-6372 (June 1970).

2. C. M. Simmons, D. L. Beshears, and M. R. Cates, Low-Temperature Phosphor Thermometry: Calibration of Europium-Doped, Lanthanum Oxysulfide Between Room Temperature and $-194^{\circ} \mathrm{C}$, ORNL/ATD-25, Martin Marietta Energy Systems, Inc., Oak Ridge Natl. Lab., February 1990.

3. S. W. Allison et al., Rare-Earth Phosphors For Remote Thermographic Applications, ORNL/ATD-12, Martin Marietta Energy Systems, Inc., Oak Ridge Natl. Lab., April 1989.

4. M.R. Cates et al., Remote Thermometry of. Moving Surfaces by Laser Induced Fluorescence of Surface-Bonded Phosphor, K/TS-11,232, Union Carbide Corp., Nuclear Division, Oak Ridge Gaseous Diffusion Plant, November 1983, and Proc. Laser Institute of America 39, 50-55 (1984).

5. K. A. Wickersheim and M. H. Sun, "Fluoroptic Thermometry," Medical Electronics, 84-91. (February 1987). 
(U)
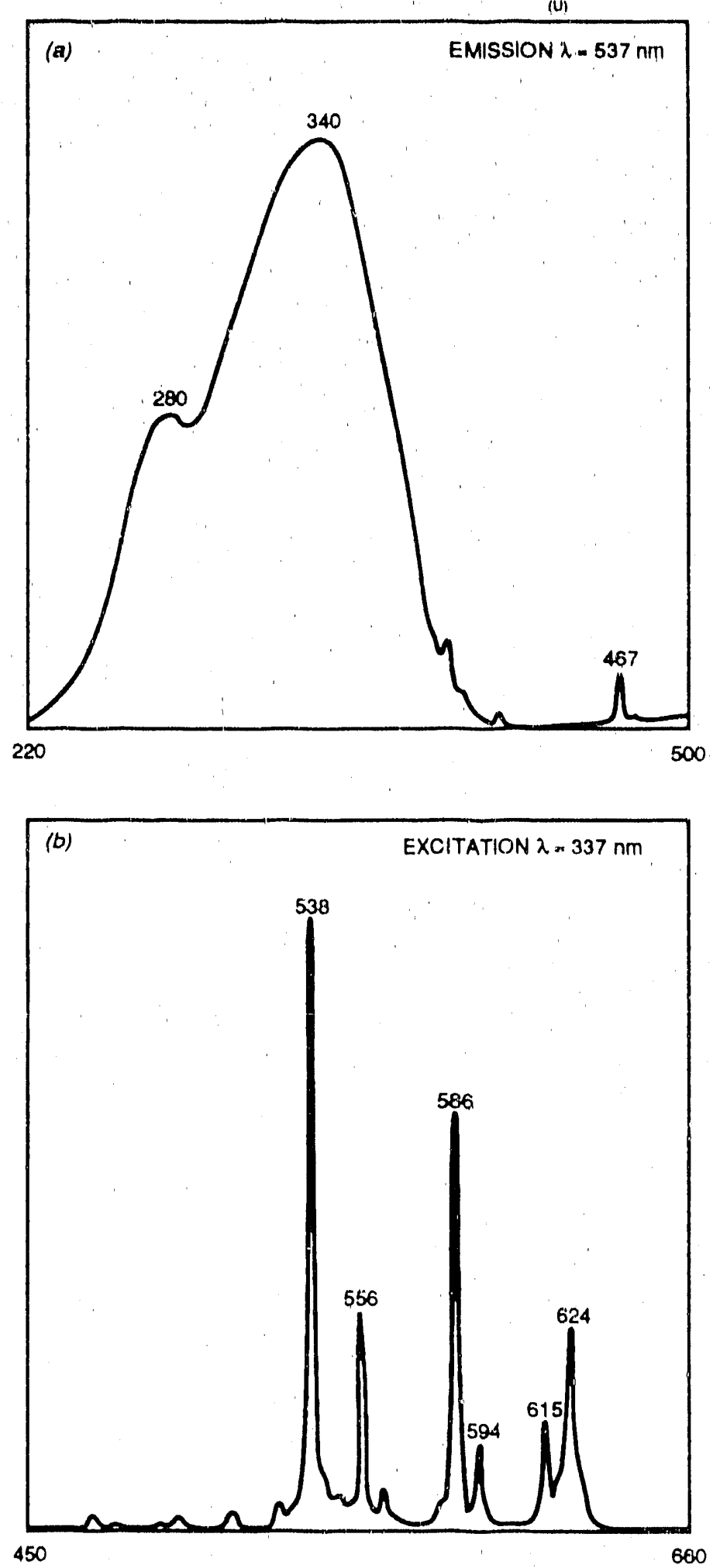

Fig. 1. Fluorescent excitation and emission spectra for $\mathrm{La}_{2} \mathrm{O}_{2} \mathrm{~S}$ : Eu at room temperature. (a) excitation spectra, (b) emission spectra. 
$1370 \quad 44$
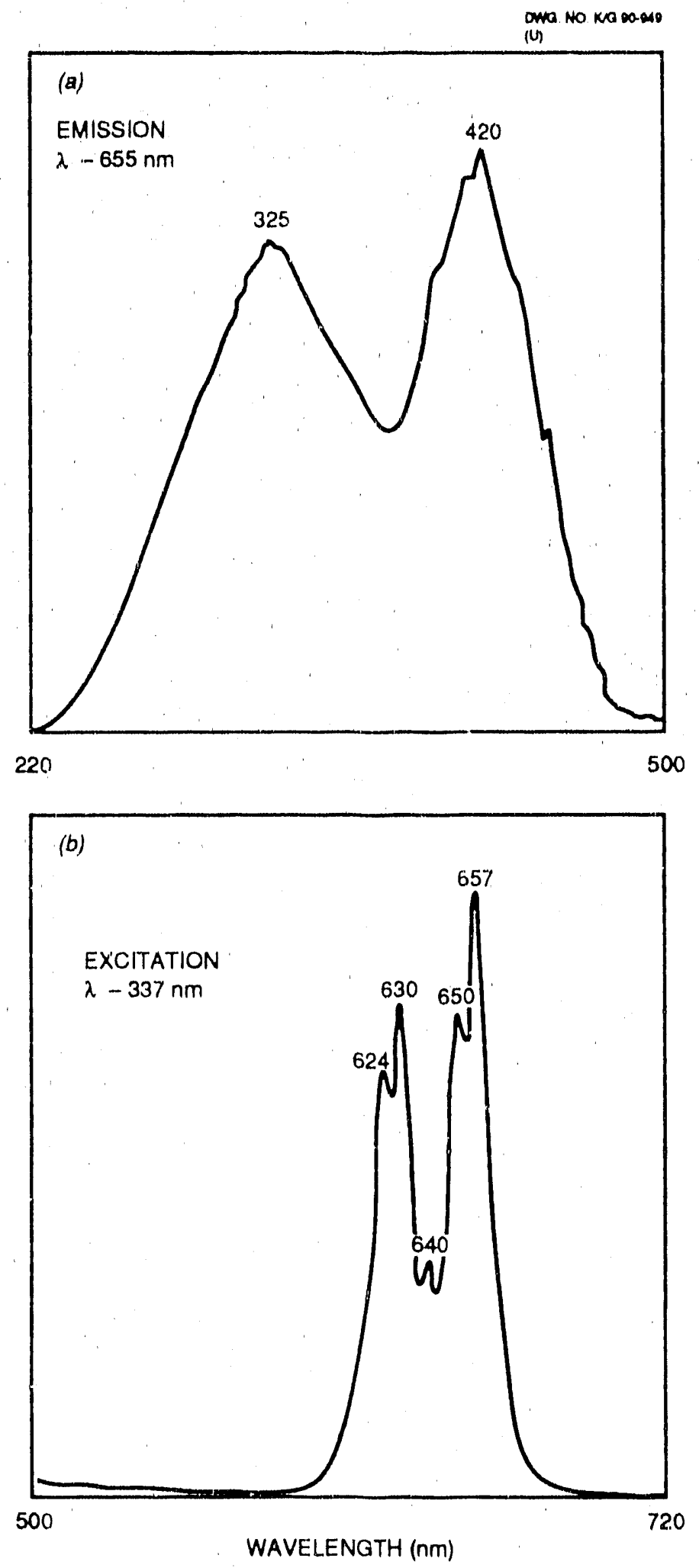

Fig. 2. Fluorescent excitation and emission spectra for $\mathrm{Mg}_{4}(\mathrm{~F}) \mathrm{GmO}_{6}: \mathrm{Mn}$ at room temperature. (a) excitation spectra, (b) emission spectra. 


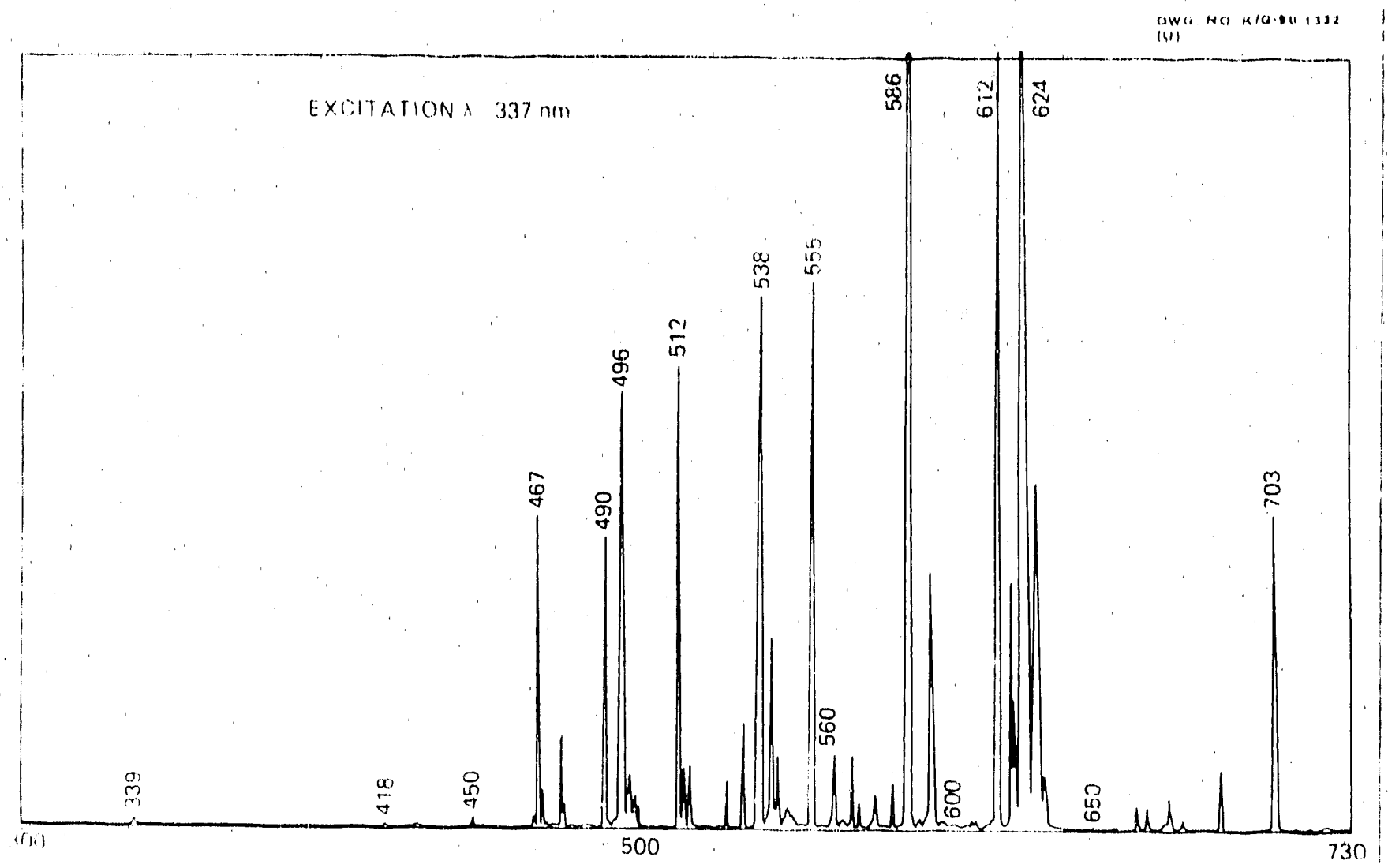

Fig. 3. Fluorescent emission spertra for $\mathrm{La}_{2} \mathrm{O}_{2} \mathrm{~S}: \mathrm{Eu}$ at $11 \mathrm{~K}$.

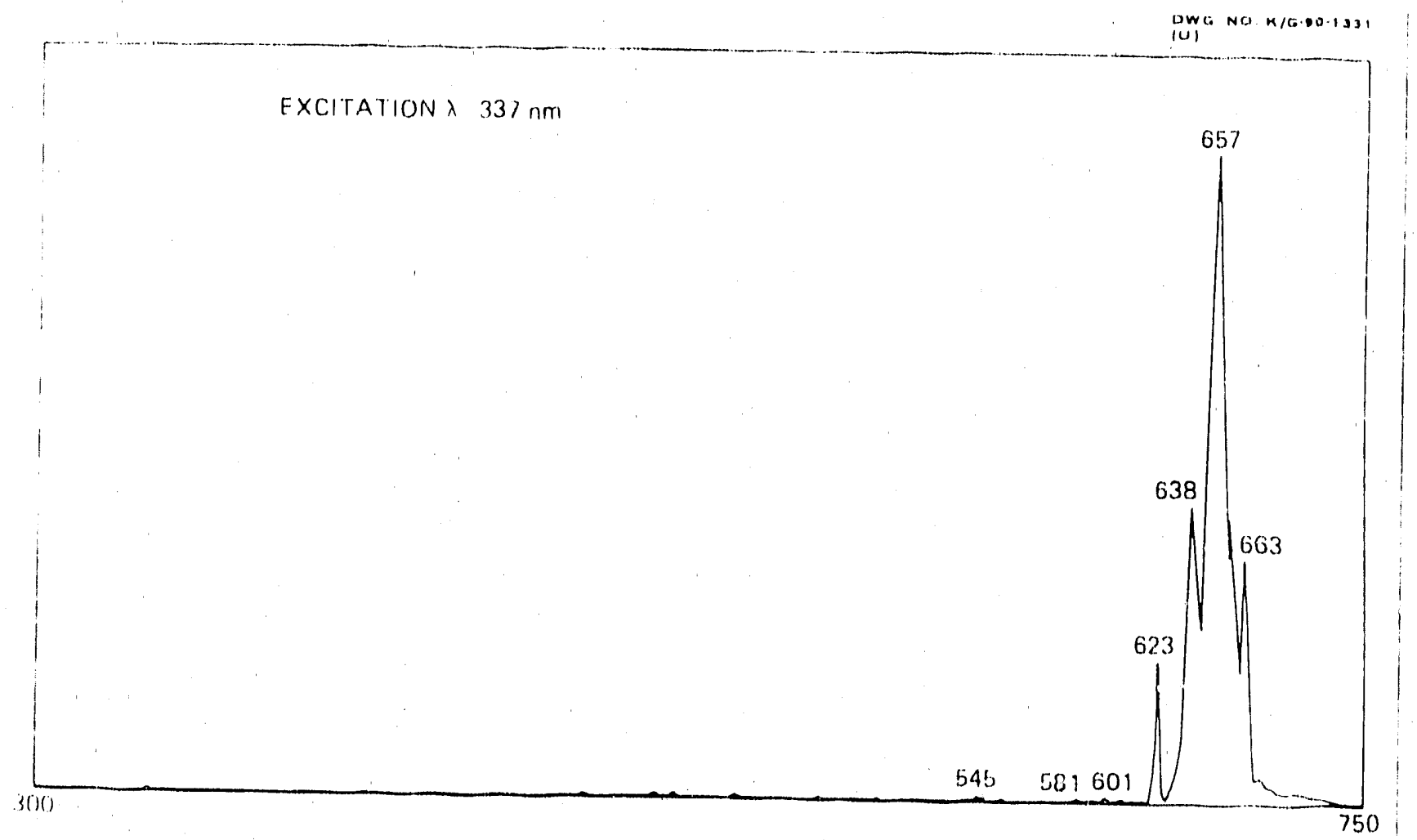

Fig. 4. Fluorescent emission spectra for $\left.\mathrm{Mg}_{4}(\mathrm{~F}) \mathrm{GmO}\right)_{6}: \mathrm{Mn}$ at $12 \mathrm{~K}$. 


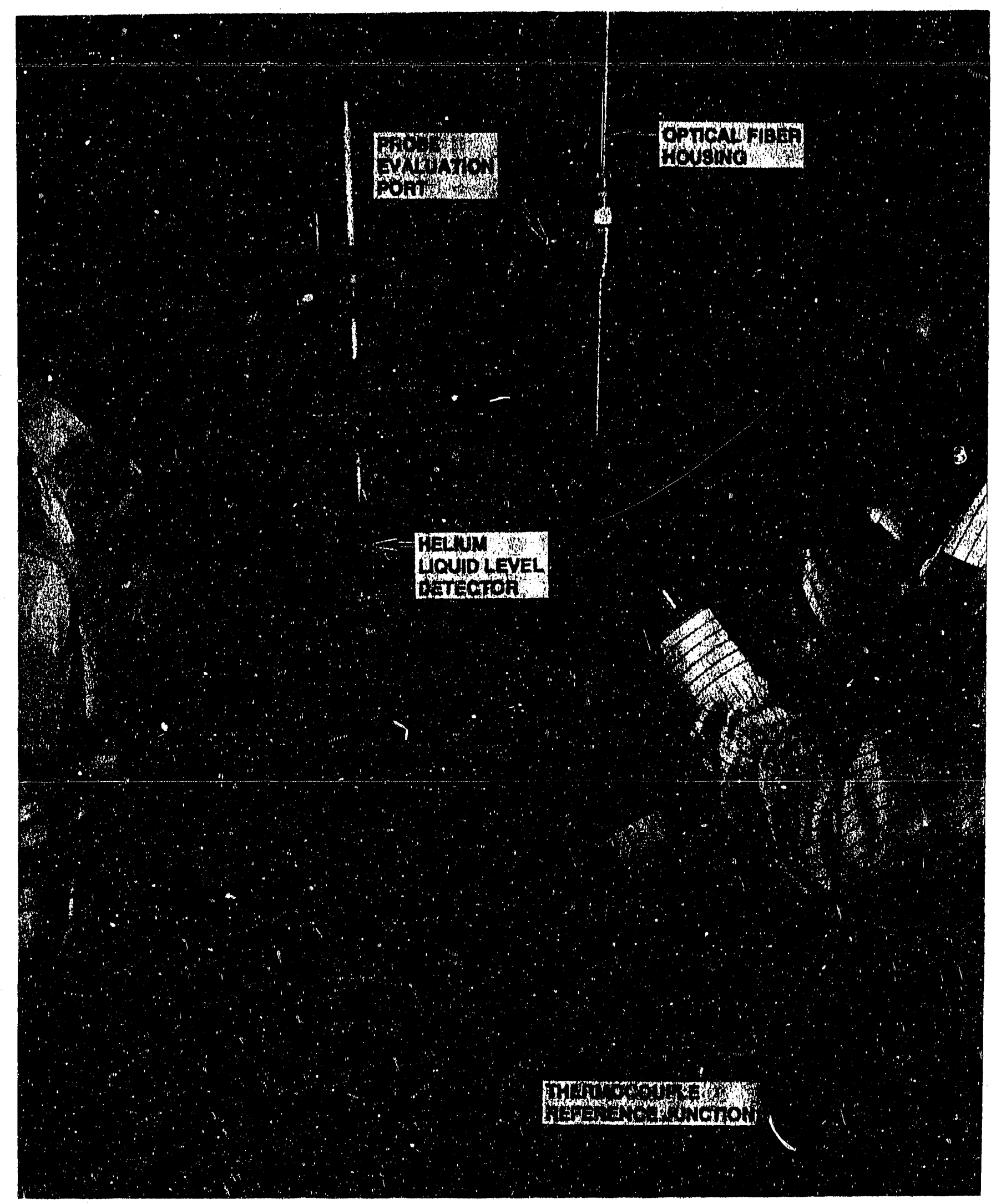

Fig. 5. Cryostat for thermographic phosphor experiments. 


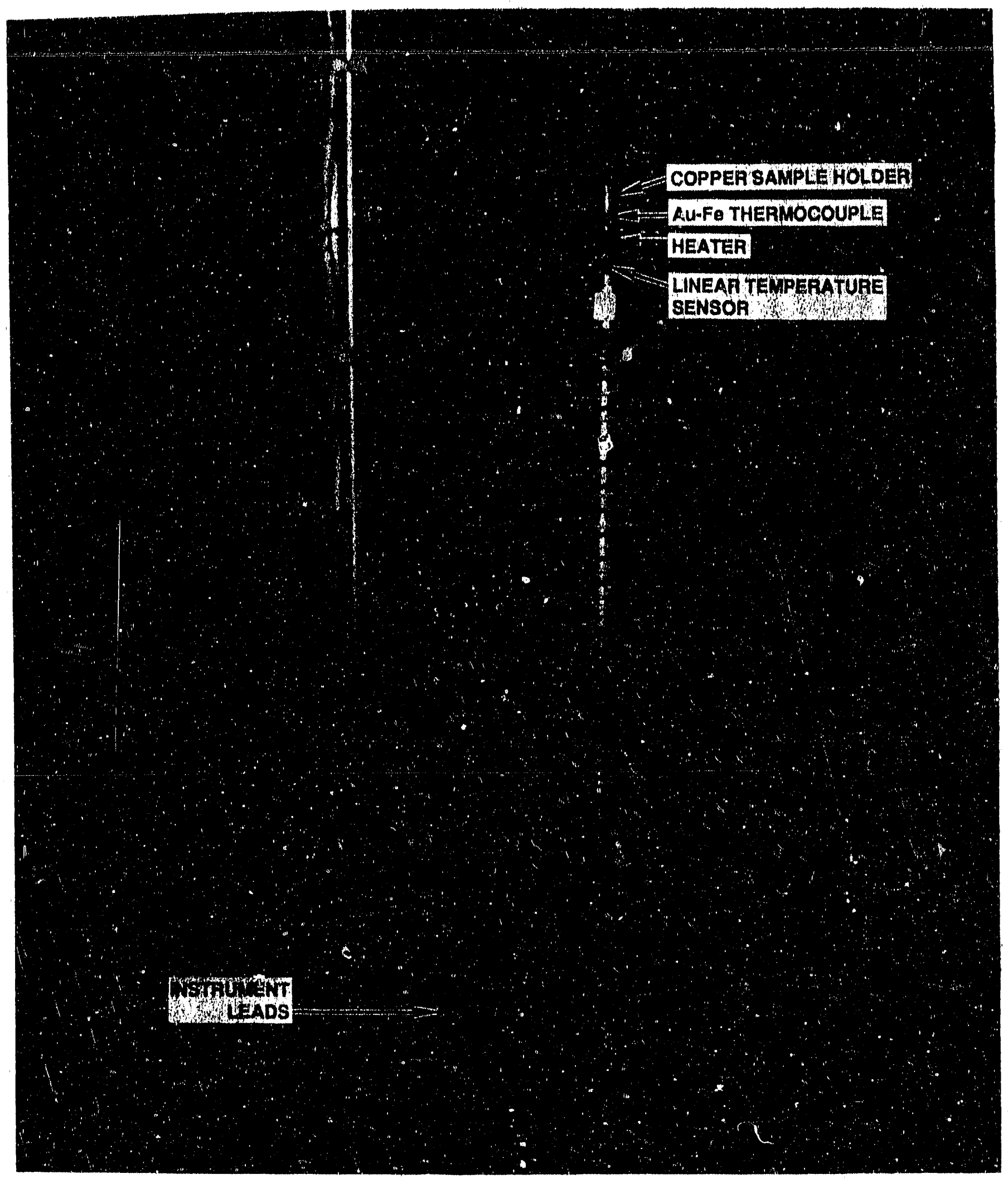

Fig. 6. Photograph of the cryostat sample holder. 

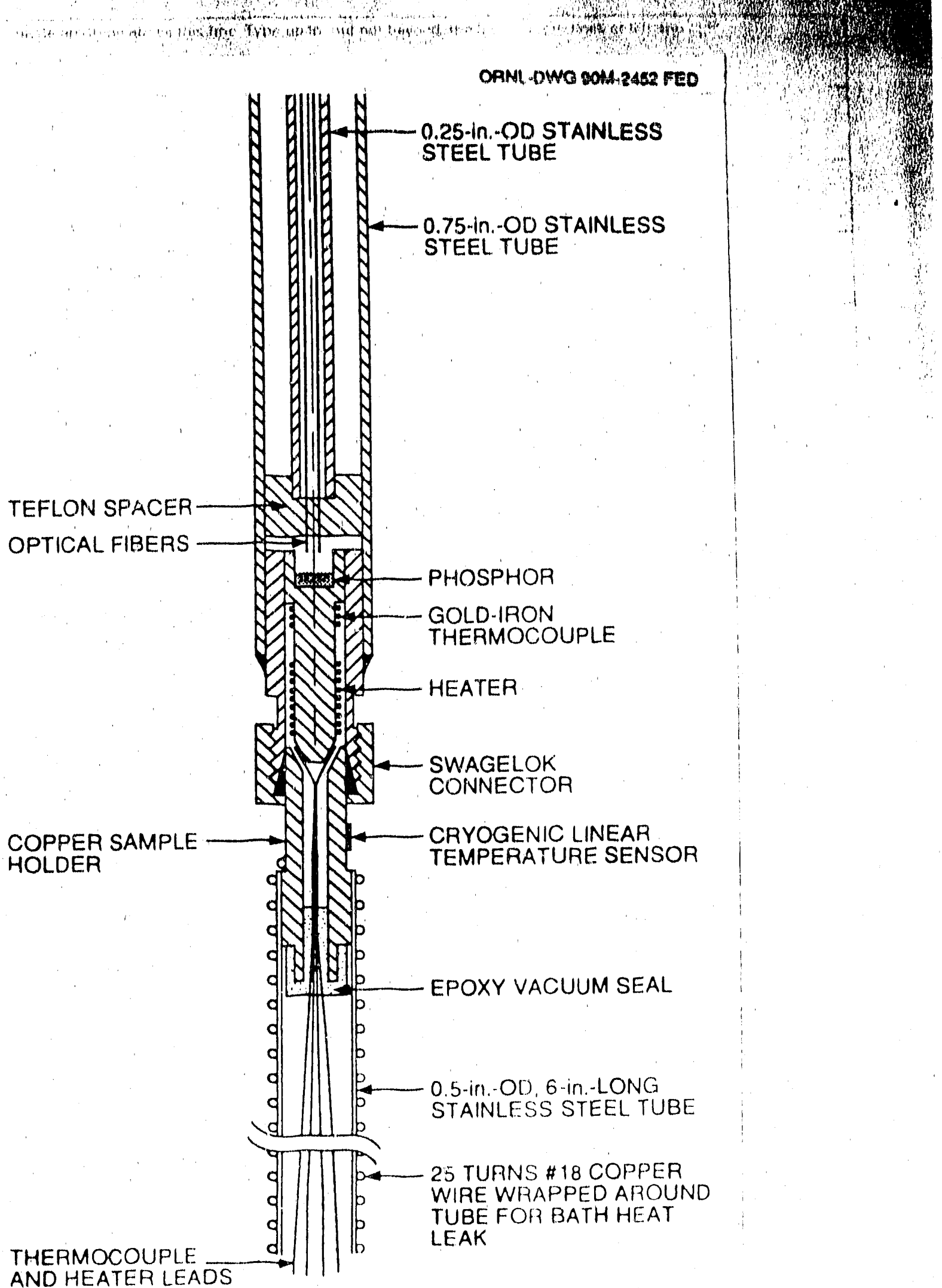

Fig. 7. Thermography sample holder. 


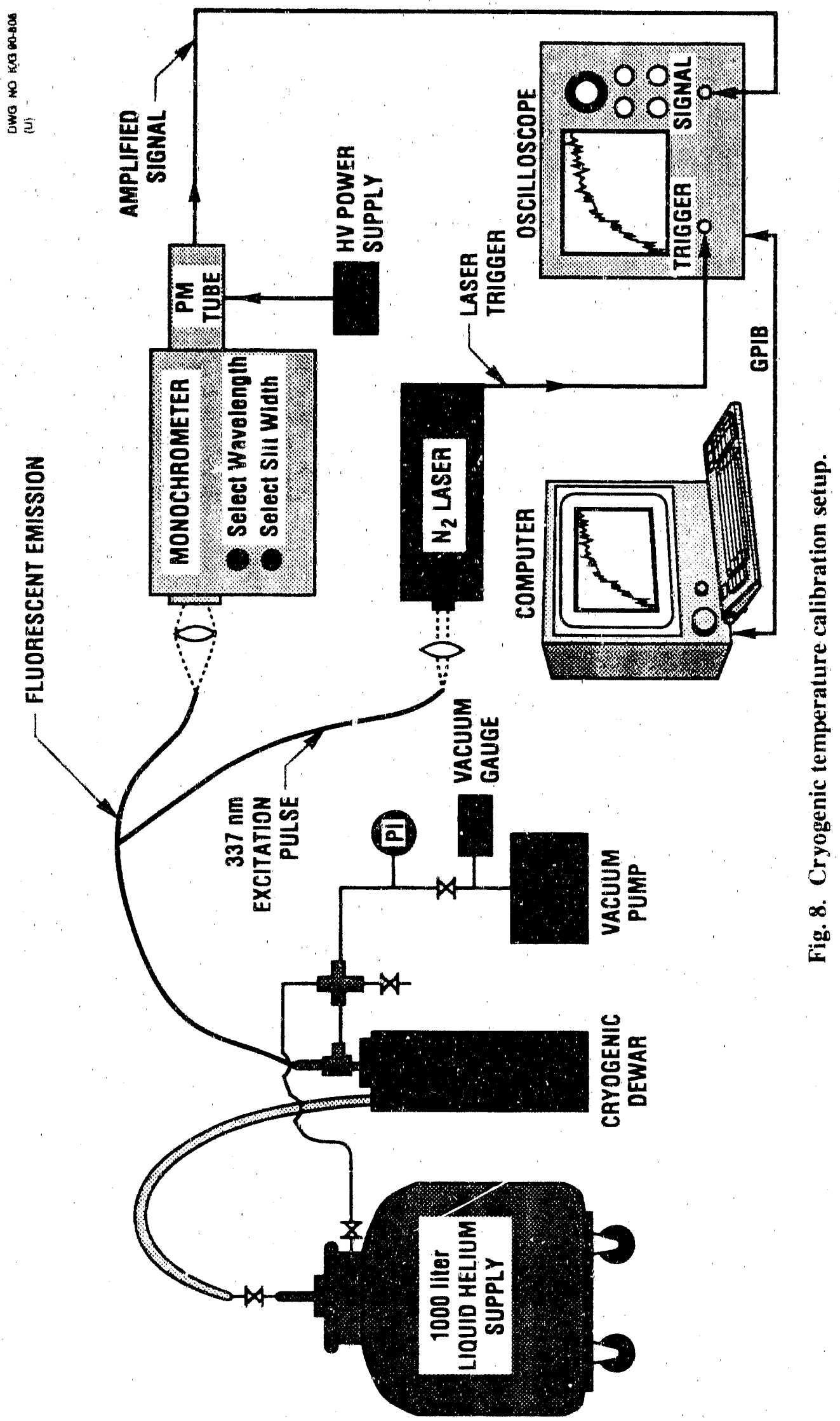




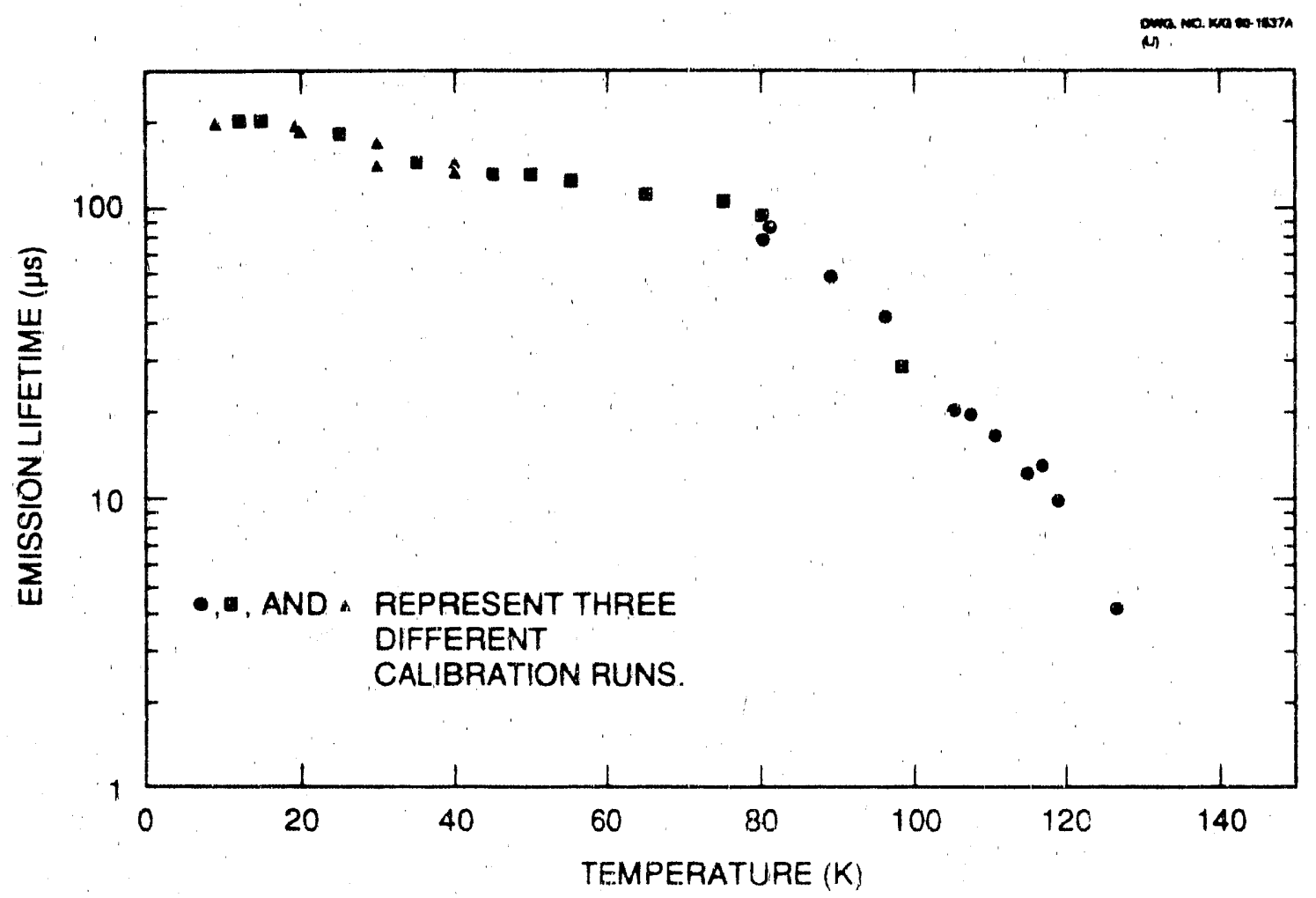

Fig. 9. $\mathrm{La}_{2} \mathrm{O}_{2} \mathrm{~S}:$ Eu phosphor calibration.

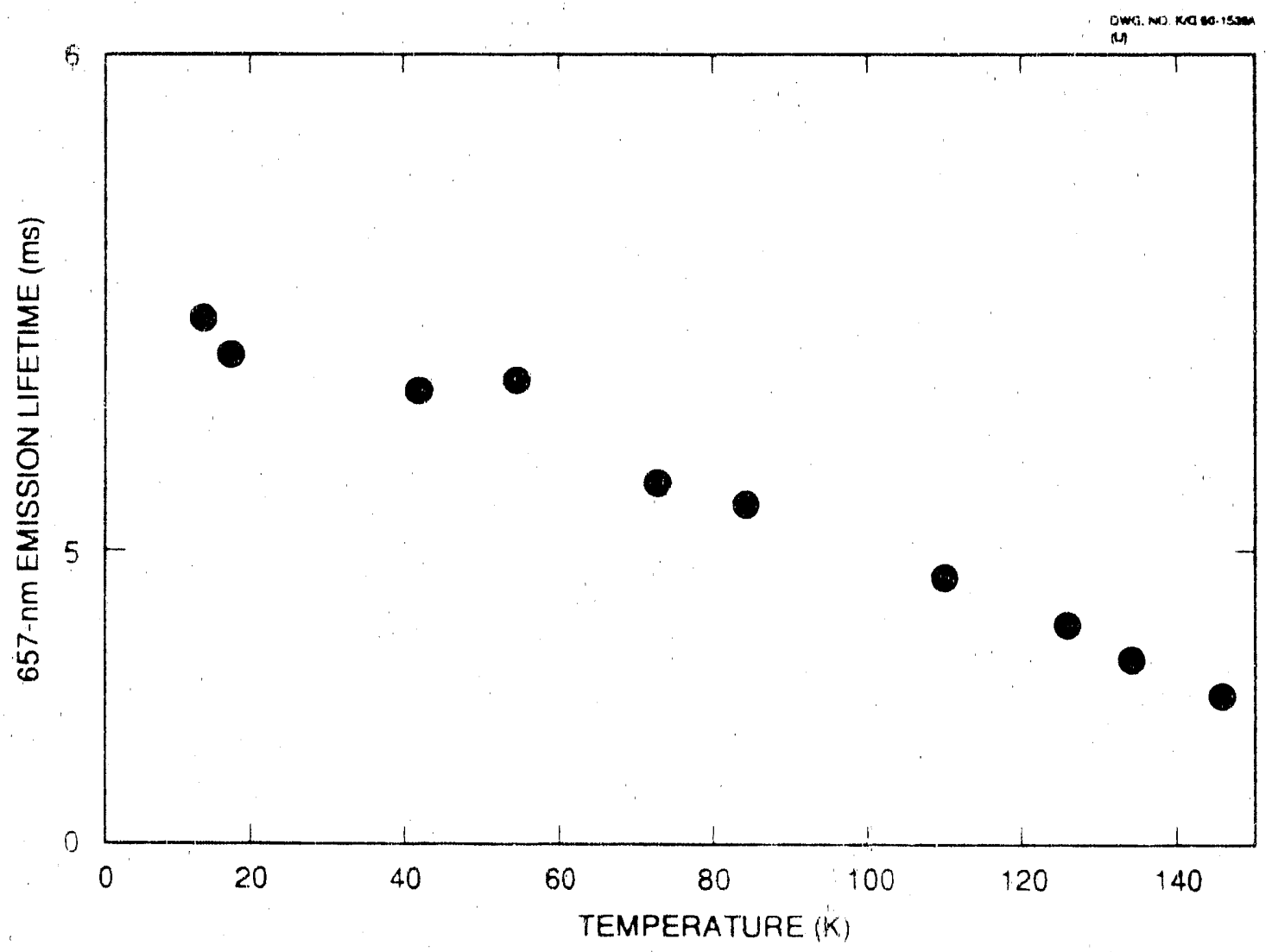

Fig. 10. $\mathrm{Mg}_{4}(\mathrm{~F}) \mathrm{GeO}$ : Mn phosphor caibration. 

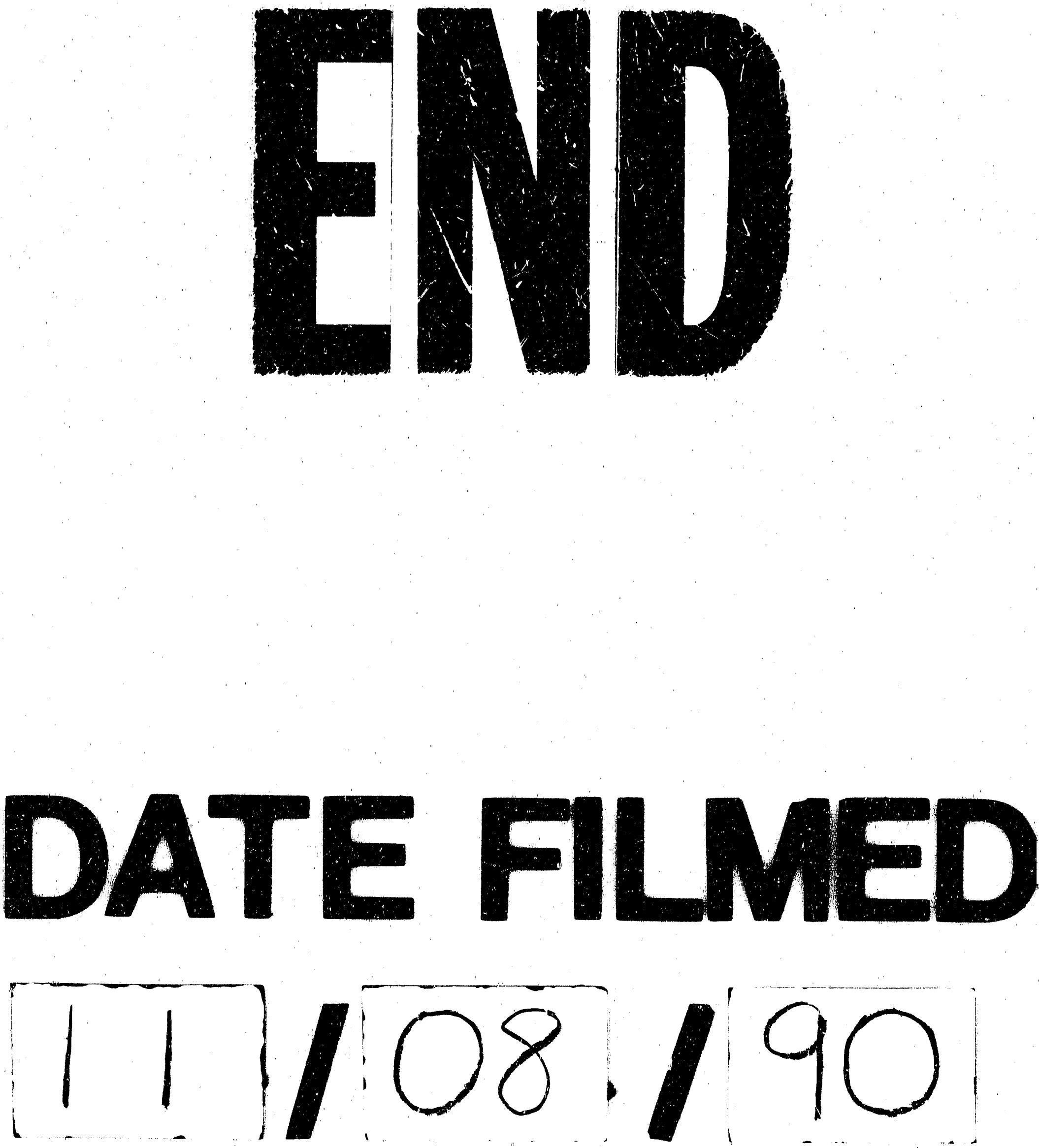
